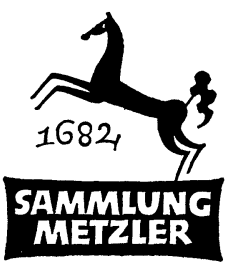

REALIENBÜCHER FÜR GERMANISTEN

ABT. D :

LITERAT URGESCHICHTE 
DOMINIK JOST

\section{Literarischer Jugendstil}

MCMLXIX

J.B. METZLERSCHE VERLAGSBUCHHANDLUNG STUTTGART 
ISBN 978-3-476-98956-7 ISBN 978-3-476-98955-0 (eBook) DOI 10.1007/978-3-476-98955-0

\section{8I}

(C) 1969 Springer-Verlag GmbH Deutschland

Ursprünglich erschienen 1969 bei J. B. Metzlersche Verlagsbuchhandlung und Carl Ernst Poeschel Verlag GmbH in Stuttgart 
I. Der Jugendstil . . . . . . . . . . . . . . . . . I

I. Begriff . . . . . . . . . . . . . . . . . . I

2. Topik . . . . . . . . . . . . . . . . . . . 6

3. Gesellschaftliche Wirklichkeit . . . . . . . . . . 9

II. Prolegomena zum literarischen Jugendstil . . . . . . I3

I. Parallelen von bildender Kunst und Literatur . . . I3

2. Der Jugendstil als Antirealismus . . . . . . . . . Is

3. Der Jugendstil als Ausformung des Manierismus . . I 8

4. Der Jugendstil als elliptischer Stil . . . . . . . . 23

III. Forschungslage und Rezeption des literarischen Jugendstils

IV. Autoren und Werke des literarischen Jugendstils . . . 4I

I. Zur Vorgeschichte und zur Geschichte . . . . . . . 4I

2. $>$ Moderner Musen-Almanach< I893 und I894 . . . 45

3. Nietzsche. George. Hofmannsthal. Rilke . . . . . 47

4. Vollmoeller. Th. Mann. Wedekind. Heym. Das literarische Chanson . . . . . . . . . . . . 52

V. Beispiele des literarischen Jugendstils . . . . . . . . 63

I. Max Dauthendey . . . . . . . . . . . . . . . 63

2. Else Lasker-Schüler . . . . . . . . . . . . . . 71

3. Ernst Stadler . . . . . . . . . . . . 75

4. Gustav Sack . . . . . . . . . . . . . . . 76

s. Eduard Stucken . . . . . . . . . . . . . . . 77

VI. Verlage und Zeitschriften des Jugendstils . . . . . . 80

Register . . . . . . . . . . . . . . . . 87 


\section{AbKüRZUNGEN}

dt. $=$ deutsch

DVjs. = Deutsche Vierteljahrsschrift für Literaturwissenschaft u. Geistesgeschichte

GRM = Germanisch-Romanische Monatsschrift

Jb. = Jahrbuch

Jh. = Jahrhundert

$\mathrm{ZfdB}=$ Zeitschrift für deutsche Bildung

$\mathrm{ZfdPh} .=$ Zeitschrift für deutsche Philologie 